\title{
Triticum mosaic virus: A Distinct Member of the Family Potyviridae with an Unusually Long Leader Sequence
}

\author{
Satyanarayana Tatineni, Amy D. Ziems, Stephen N. Wegulo, and Roy French
}

First and fourth authors: United States Department of Agriculture-Agriculture Research Service and Department of Plant Pathology; and second and third authors: Department of Plant Pathology, University of Nebraska, Lincoln 68583.

Accepted for publication 4 April 2009.

\begin{abstract}
Tatineni, S., Ziems, A. D., Wegulo, S. N., and French, R. 2009. Triticum mosaic virus: A distinct member of the family Potyviridae with an unusually long leader sequence. Phytopathology 99:943-950.

The complete genome sequence of Triticum mosaic virus (TriMV), a member in the family Potyviridae, has been determined to be 10,266 nucleotides (nt) excluding the $3^{\prime}$ polyadenylated tail. The genome encodes a large polyprotein of 3,112 amino acids with the "hall-mark proteins" of potyviruses, including a small overlapping gene, PIPO, in the P3 cistron. The genome of TriMV has an unusually long 5' nontranslated region of 739 nt with 12 translation initiation codons and three small open reading frames, which resemble those of the internal ribosome entry site containing $5^{\prime}$ leader sequences of the members of Picornaviridae. Pairwise comparison of 10 putative mature proteins of TriMV with those of representative members of genera in the family Potyviridae revealed 33
\end{abstract}

ABSTRACT

Viruses from several different families infect wheat (Triticum aestivum L.) in the Great Plains and other parts of the United States. These viruses include Agropyron mosaic virus (AgMV), Barley yellow dwarf virus, Soil-borne wheat mosaic virus, Triticum mosaic virus (TriMV), Wheat American striate mosaic virus, Wheat mosaic virus, and Wheat streak mosaic virus (WSMV) $(6,20,21)$. Among these viruses, WSMV is an economically important virus causing significant yield losses in the United States (6). TriMV was recently reported from Kansas, naturally infecting WSMV-resistant wheat cultivars (20); however, the impact of this virus on yield losses in wheat remains to be known.

The Potyviridae is the largest family of positive-stranded RNA viruses infecting plants, divided into six genera based on their genetic relatedness, vector transmission, and genome organization $(2,5)$. The genus Potyvirus, with Potato virus Y (PVY) as the type member, contains numerous economically important aphidtransmitted virus species and is the most thoroughly characterized genus among the family Potyviridae. Other genera include Rymovirus, with Ryegrass mosaic virus (RGMV) as the type species, transmitted by Abacarus mites; Tritimovirus, with WSMV as the type member, vectored by wheat curl mites (Aceria tosichella); Ipomovirus, with Sweet potato mild mottle virus (SPMMV) as the type species, transmitted by whiteflies; and Macluravirus, with Maclura mosaic virus (MacMV) as the type species, with charac-

Corresponding author: S. Tatineni

E-mail address: Satyanarayana.tatineni@ars.usda.gov

doi:10.1094/PHYTO-99-8-0943

This article is in the public domain and not copyrightable. It may be freely reprinted with customary crediting of the source. The American Phytopathological Society, 2009. to $44 \%$ amino acid identity within the highly conserved NIb protein sequence and 15 to $29 \%$ amino acid identity within the least conserved P1 protein, suggesting that TriMV is a distinct member in the family Potyviridae. In contrast, TriMV displayed 47 to $65 \%$ amino acid sequence identity with available sequences of mature proteins of Sugarcane streak mosaic virus (SCSMV), an unassigned member of the Potyviridae. Phylogenetic analyses of the complete polyprotein, NIa-Pro, NIb, and coat protein sequences of representative species of six genera and unassigned members of the family Potyviridae suggested that TriMV and SCSMV are sister taxa and share a most recent common ancestor with tritimoviruses or ipomoviruses. These results suggest that TriMV and SCSMV should be classified in a new genus, and we propose the genus Poacevirus in the family Potyviridae, with TriMV as the type member.

Additional keyword: wheat.

teristic short virus particles transmitted by aphids. These five genera all contain monopartite viruses, whereas the genus Bymovirus, with Barley yellow mosaic virus (BaYMV) as the type member, contains bipartite viruses transmitted by plasmodiophorids. Additionally, there are several unassigned members which may warrant separate genera in the family Potyviridae. Blackberry virus Y (BIVY) (23) and Spartina mottle virus (9) do not belong to any of the existing genera. Sugarcane streak mosaic virus (SCSMV) was initially reported as a possible member of the genus Tritimovirus $(10,11)$, but subsequent phylogenetic analyses concluded that SCSMV is an additional unassigned member in the family Potyviridae $(12,17)$.

During 2006, temperature-sensitive WSMV-resistant wheat cultivars produced virus-like symptoms in Kansas, and the causal agent was characterized and identified as TriMV in the family Potyviridae (20). The coat protein (CP) of TriMV showed 49\% amino acid sequence identity with that of SCSMV (20). Recently, Seifers et al. (19) reported the wheat curl mite, which also transmits WSMV, as the vector of TriMV. During the 2008 growing season, $\approx 30 \%$ of wheat samples submitted to the University of Nebraska-Lincoln Plant and Pest Diagnostic Clinic tested positive for TriMV (28), which warranted the molecular characterization of this new virus. As a first step in this direction, we report the complete genome sequence of TriMV, the amino acid sequence comparison of its polyprotein and predicted mature proteins, and phylogenetic analysis with representative members in six genera and unassigned members of the family Potyviridae. Our results provide evidence that TriMV is a distinct species in the family Potyviridae, with an unusually long $5^{\prime}$ nontranslated region (NTR) (739 nucleotides [nt]), and is proposed as the type member of a new genus Poacevirus in the family Potyviridae. 


\section{MATERIALS AND METHODS}

Virus source. Wheat plants with mosaic and chlorotic streak symptoms collected from Red Willow County, Nebraska that failed to react with WSMV antiserum but positively reacted with TriMV antiserum in double-antibody sandwich enzyme-linked immunosorbent assay (DAS-ELISA) (Agdia, Elkhart, IN) provided the virus source for the present investigation. A pure culture of TriMV was obtained by inoculating crude sap from this virus isolate at high dilutions $(1: 6,600)$ to single-leaf stage wheat seedlings (cv. Tomahawk) for three successive passages. Briefly, virus inoculum was prepared by grinding infected wheat leaves in $20 \mathrm{mM}$ sodium phosphate buffer, $\mathrm{pH} 7.0$ (inoculation buffer), and further diluted to 1:6,600 in inoculation buffer. At each passage, individual infected wheat plants that reacted positively with TriMV antiserum in DAS-ELISA were used as the source of inoculum for the next passage.

Virus purification and isolation of viral RNA. Wheat (cv. Tomahawk) leaves infected with TriMV at 14 to 17 days postinoculation (dpi) showing mosaic and chlorotic streak symptoms were used to partially purify virions as described by Lane (14) with slight modifications. Briefly, frozen infected tissue (20 to $25 \mathrm{~g}$ ) was ground in an electric blender in $0.1 \mathrm{M}$ sodium citrate buffer, pH 6.5 (SCB) containing $0.1 \% \beta$-mercaptoethanol $(4 \mathrm{ml} / \mathrm{g}$ of tissue). The extract was filtered through four layers of muslin cloth and clarified at $7,700 \times g$ for $10 \mathrm{~min}$. The supernatant was treated with $2 \%$ Triton-X 100 at $4^{\circ} \mathrm{C}$ for 5 to $10 \mathrm{~min}$ and layered on $5 \mathrm{ml}$ of $20 \%$ sucrose (wt/vol) in SCB. The virus particles were concentrated by centrifugation at $118,000 \times g$ for $1.5 \mathrm{~h}$ in a Beckman 50.2 Ti rotor. The virus pellet was resuspended in $18 \mathrm{ml}$ of cold SCB and clarified by low-speed centrifugation at 7,700 $\times$ $g$ for $10 \mathrm{~min}$. Virions from the supernatant $(9 \mathrm{ml})$ were further concentrated by centrifugation $(139,000 \times g$ for $1.5 \mathrm{~h}$ in a Beckman 70.2 Ti rotor) through a $1-\mathrm{ml}$ cushion of $20 \%$ sucrose. Virions were recovered by suspending the pellet in $400 \mu \mathrm{l}$ of suspension buffer (10 mM Tris-Cl, $\mathrm{pH} 8.0 ; 1 \mathrm{mM}$ EDTA; and $100 \mathrm{mM} \mathrm{NaCl}$ ). All centrifugation steps were carried out at $4^{\circ} \mathrm{C}$.

Viral RNA was isolated from partially purified virus by treating with $1 \%$ sodium dodecyl sulfate and proteinase $\mathrm{K}$ at $200 \mu \mathrm{g} / \mathrm{ml}$ (Ambion, Austin, TX) at $50^{\circ} \mathrm{C}$ for $20 \mathrm{~min}$, followed by two phenol-chloroform extractions and ethanol precipitation. Polyadenylated viral RNA was purified further by passing viral RNA through an Illustra mRNA purification oligo(dT) column (GE Healthcare, Waukesha, WI). The viral RNAs were analyzed on a $0.9 \%$ agarose gel containing $10 \mathrm{mM}$ methyl mercury hydroxide (3).

cDNA synthesis and molecular cloning of TriMV genome. TriMV RNA isolated from partially purified virions, followed by oligo(dT)-cellulose column purification, was used as the template for reverse transcription with the combination of oligo dT and random hexamers as primers. The SuperScript Choice System for cDNA synthesis kit (Invitrogen, Carlsbad, CA) was used to make the first-strand cDNA, followed by second-strand synthesis as per the instructions provided with the kit. EcoRI (NotI) adaptors were ligated to double-stranded (ds)DNA products of second-strand reaction, followed by passage through column chromatography to select larger dsDNA products. The dsDNA products with EcoRI (NotI) adaptors were ligated into EcoRI-cut dephosphorylated pGEM-7Zf(-) (Promega Corporation, Madison, WI), followed by transformation into Escherichia coli JM109. The inserts were characterized by restriction enzyme digestion with EcoRI, HindIII, NotI, NcoI, and PstI, and cDNA clones with insert size $>2.0 \mathrm{kbp}$ were selected for further sequencing.

Reverse-transcription polymerase chain reaction amplification. Sequences obtained from cDNA clones aligned into two contigs and comparison of these sequences with reported genome sequence of WSMV (22) revealed a gap in the genome sequence of TriMV. This gap was amplified by reverse-transcription polymerase chain reaction (RT-PCR), followed by cloning and se- quencing. An oligonucleotide, Tr-1, complementary to nucleotides 5457 to 5425 , was used for reverse transcription with SuperScript II RT, followed by PCR amplification with oligonucleotides Tr-2, corresponding to nucleotides 2292 to 2324, and Tr1 using Taq DNA polymerase. PCR conditions used for $5^{\prime}$ rapid amplification of cDNA ends (RACE) were also used for RT-PCR, except for a 3 -min extension time at $72^{\circ} \mathrm{C}$ (see below). The RTPCR product was ligated into pGEM-Teasy vector (Promega Corporation) and three independent clones were sequenced completely in both directions. The consensus sequence of RT-PCR clones was used to fill the gap in the genome sequence of TriMV.

Determination of the $5^{\prime}$ end sequence of the genomic RNA. The exact $5^{\prime}$ end sequence of TriMV was determined using viral RNA isolated from partially purified virions as the template with the 5' RACE system (Invitrogen). First-strand cDNA synthesis was performed using the gene-specific primer 1 (GSP1) (5'-CCAAGATACTGCACACAAGAAATTGAACAAAAT-3', complementary to nucleotides 1240 to 1208), and unincorporated nucleotides and GSP1 primer were removed using sodium iodide, followed by column purification as per the instructions in the kit. The 3 ' end of the purified first-strand cDNA was ' $C$ ' tailed using terminal deoxynucleotidyl transferase (TdT), and TriMV-specific DNA was amplified using GSP2 (5'-CTGTAAGTATGAGCAGCATATCGTTTCAACATT-3', complementary to nucleotides 1197 to 1165) and abridged anchor primer (AAP, supplied with kit) using Taq DNA polymerase $(2.5 \mathrm{U})$ for 1 cycle at $94^{\circ} \mathrm{C}$ for $2 \mathrm{~min}$; followed by 35 cycles at $94^{\circ} \mathrm{C}$ for $20 \mathrm{~s}, 55^{\circ} \mathrm{C}$ for $20 \mathrm{~s}$ and $72^{\circ} \mathrm{C}$ for $2 \mathrm{~min}$; and 1 cycle at $72^{\circ} \mathrm{C}$ for $10 \mathrm{~min}$. The $5^{\prime} \mathrm{RACE}$ PCR product was ligated into pGEM-Teasy vector (Promega Corporation) and the inserts were sequenced.

RT-PCR was performed to further examine the authenticity of the length of the 5' NTR of TriMV. RNA isolated from virions was reverse transcribed with oligonulceotide Tr-26 (complementary to nucleotides 1234 to 1217 ), followed by PCR amplification with oligonucleotides $\operatorname{Tr}-16$ (corresponding to nucleotides 1 to 33 ) in combination with Tr-18 (complementary to nucleotides 829 to 812 ) or $\operatorname{Tr}-22$ (complementary to nucleotides 1009 to 992 ) or Tr-26. PCR was performed with the same conditions that were used for the 5' RACE system except for using Herculase II Fusion DNA polymerase (Stratagene, La Jolla, CA). The RT-PCR products were analyzed on a $1.0 \%$ agarose gel in $1 \times$ Tris-acetate EDTA buffer (40 mM Tris-acetate, $\mathrm{pH} 8.3$, and 1 mM EDTA).

Nucleotide sequencing and sequence analyses. Sequencing of TriMV cDNA, RT-PCR, and 5' RACE clones was carried out at the University of Florida ICBR Core DNA Sequencing Facility using an Applied Biosystems 3730 model sequencer. Both strands of TriMV clones were sequenced by the primer walking method. Contig sequences were created from individual sequences of cDNA, RT-PCR, and 5' RACE clones using Sequencher 4.1 (Gene Codes, Ann Arbor, MI). Both strands of at least two to three independent clones covering the entire genome were sequenced to obtain the sequence of genomic RNA. Additionally, sequences of 12 independent cDNA and 5' RACE clones were used to obtain an unambiguous sequence of the $5^{\prime}$ end of the genomic RNA.

Pairwise sequence comparisons of TriMV mature proteins with selected members of the family Potyviridae were carried out using the ALIGN program of online analysis tools (http://molbioltools.ca). Multiple sequence alignments were performed with the ClustalW program (25), and the MEGA 4.0 analysis package (24) was used to perform phylogenetic analysis with the neighborjoining (NJ) method using the JTT matrix and pairwise gap deletion, with 1,000 bootstrap replicates as the test of phylogeny.

\section{RESULTS}

Analysis of viral RNA. TriMV RNA extracted from partially purified virions was separated into a single band on $0.9 \%$ agarose 
gel containing $10 \mathrm{mM}$ methyl mercury hydroxide (Fig. 1, lane 1). The size of TriMV RNA was estimated to be $\approx 10.0 \mathrm{~kb}$ based on RNA molecular size markers (Invitrogen) and WSMV RNA. WSMV virion RNA $(9.3 \mathrm{~kb})$ was included in agarose gel as the

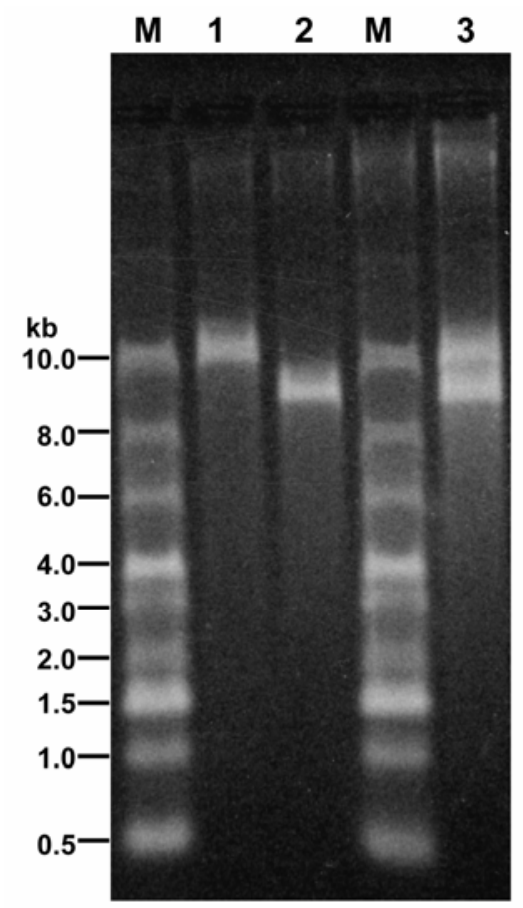

Fig. 1. Analysis of Triticum mosaic virus (TriMV) RNA through 1.0\% agarose gel in the presence of $10 \mathrm{mM}$ methyl mercury hydroxide. Lane M: RNA size markers (Invitrogen); lane 1: TriMV RNA; lane 2: Wheat streak mosaic virus (WSMV) RNA; lane 3: co-migration of TriMV and WSMV RNAs. Note the slow migration of TriMV RNA when compared with 9.3-kb RNA of WSMV (compare lanes 1 and 2; and lane 3). reference standard, which migrated slightly faster than that of TriMV RNA (Fig. 1, lanes 2 and 3). Taken together, agarose gel electrophoresis of viral RNA and genome sequencing (see below) indicated that the RNA genome of TriMV is $\approx 1.0 \mathrm{~kb}$ longer than that of WSMV.

Genome organization of TriMV. The complete nucleotide sequence of TriMV genomic RNA was assembled from the sequence of multiple overlapping cDNA, RT-PCR, and 5' RACE clones (Fig. 2). The sequence of TriMV genomic RNA was determined to be $10,266 \mathrm{nt}$, excluding the variable-length polyadenylated tail at the $3^{\prime}$ end of the genomic RNA. The genome sequence has been deposited in GenBank with the accession number FJ669487. The genome organization of TriMV is typical of monopartite viruses of the family Potyviridae, with one large open reading frame (ORF), which initiates (AUG) at nucleotide positions 740 to 742 and terminates with a stop codon (UAG) at nucleotide positions 10076 to 10078 (Fig. 2). The large ORF encodes a polyprotein of 3,112 amino acids with a predicted molecular weight of $352.9 \mathrm{kDa}$.

Examination of TriMV polyprotein, followed by comparison with those of WSMV, Brome streak mosaic virus (BrSMV) (genus Tritimovirus), and Turnip mosaic virus (TuMV) (genus Potyvirus), revealed potential viral-encoded proteinase cleavage sites in the polyprotein (Table 1). Processing of the polyprotein at these cleavage sites would result in the production of mature "hallmark" proteins of potyviruses-P1, HC-Pro, P3, 6K1, CI, 6K2, NIa-VPg, NIa-Pro, NIb, and CP-as in other species of the genera Potyvirus, Rymovirus, Tritimovirus, and Ipomovirus (Sweet potato mild mottle virus) (Fig. 2). P1 and HC-Pro proteinases of TriMV likely autocatalytically cleave at predicted cleavage sites to produce mature P1 and HC-Pro, respectively. As reported in other potyviruses, NIa-Proteinase is likely responsible for the cleavages in the C-terminal two-thirds of the polyprotein at predicted cleavage sites (Table 1), which would result in release of the remaining mature proteins. The predicted cleavage sites of NIa-Pro are unusual in that they contain a conserved histidine $(\mathrm{H})$ at the -1 position (Table 1 ) rather than the typical gluta-

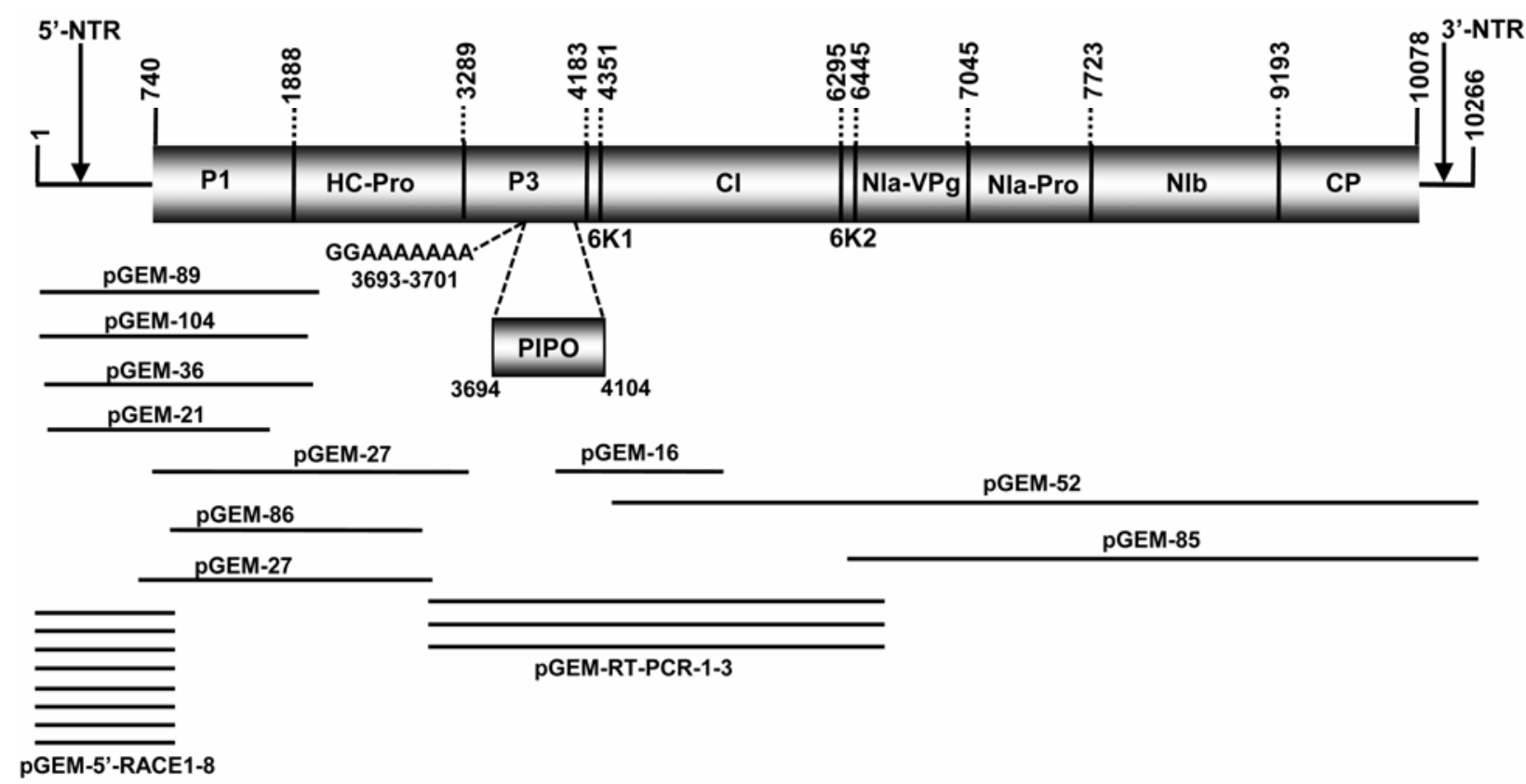

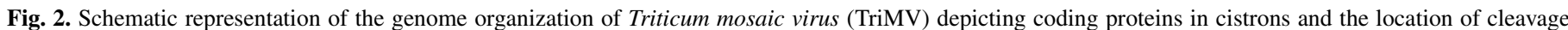

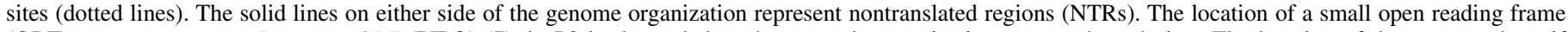

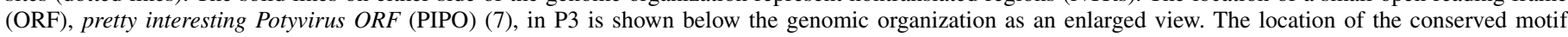

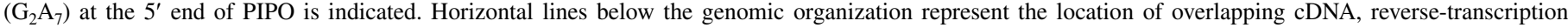

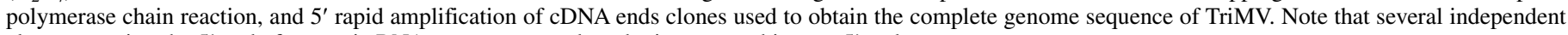
clones covering the $5^{\prime}$ end of genomic RNA were sequenced to obtain an unambiguous $5^{\prime}$ end sequence. 
mine $(\mathrm{Q})$ or glutamic acid (E) found with almost all other potyviruses (1).

Blast searches revealed potyviral conserved motifs in the TriMV polyprotein, including protease domains in P1, HC-Pro, and NIa; helicase domain in CI; polymerase motifs in NIb; and potyviral coat protein motifs in CP. We also found a conserved tyrosine residue at amino acid position 1979 in TriMV polyprotein, which is present in the same location as in Tobacco etch virus (TEV) that forms the phosphodiester linkage of VPg to the 5 ' end of the viral RNA (18).

Recently, Chung et al. (7) reported an overlapping essential gene in the P3 cistron in the family Potyviridae, which was termed the pretty interesting Potyviridae ORF (PIPO). PIPO is expressed as a P3-PIPO fusion product via ribosomal frameshifting or transcriptional slippage at a conserved $\mathrm{G}_{1-2} \mathrm{~A}_{6-7}$ motif at the $5^{\prime}$ end of PIPO (7). Analysis of the TriMV genome also revealed a conserved $\mathrm{G}_{2} \mathrm{~A}_{7}$ motif (nucleotides 3693 to 3701) in the P3 cistron similar to other reported members of the Potyviridae (Fig. 2). The P3-PIPO fusion product consists of 135 amino acids of P3 (nucleotides 3290 to 3695) and 136 amino acids of PIPO (nucleotides 3694 to 4104) (Fig. 2). Pairwise comparison of the TriMV PIPO protein sequence with those of representative members of Potyviridae revealed no significant amino acid identity (data not shown).

The $3^{\prime}$ NTR of TriMV is 188 nt long excluding the polyadenylated tail, which is similar to lengths reported for other potyviruses. The $3^{\prime}$ NTR shares $51 \%$ nucleotide sequence identity with that of SCSMV and only 30 to $44 \%$ nucleotide identity with the $3^{\prime}$ NTRs of other reported members of Potyviridae.

TriMV contains 739-nt leader sequence. The exact $5^{\prime}$ end sequence of TriMV genomic RNA was determined using the $5^{\prime}$ RACE system. Based on the fact that the $5^{\prime}$ NTRs of reported potyviruses range are 112 (RGMV) to $184 \mathrm{nt}$ (PVY), we designed a gene-specific primer $\approx 500 \mathrm{nt}$ inside the $\mathrm{P} 1$ coding region for the $5^{\prime}$ RACE system, expecting a PCR product of $\approx 650 \mathrm{bp}$. In contrast, we obtained a single RT-PCR product of $\approx 1,200 \mathrm{bp}$ (Fig. $3 \mathrm{~A})$, which was cloned into pGEM-Teasy vector. Eight independent clones were sequenced and all eight clones possess identical sequences, with the extreme $5^{\prime}$ end sequence as $5^{\prime}$-AAAAUU..... (Fig. 4A). The contig sequence obtained from 5' RACE and cDNA clones revealed that TriMV contains an unusually long leader sequence of $739 \mathrm{nt}$ (Fig. 4A). The $5^{\prime}$ NTR is A-U rich (25\% As and $33 \% \mathrm{Us})$, as in other potyviruses with no significant homology with reported potyviruses.

Because the 5' NTR of TriMV is unusually long relative to other members of the family Potyviridae, we further examined its authenticity by RT-PCR amplification using virion RNA as the template, with a forward primer located at the extreme $5^{\prime}$ end of the genomic RNA (Tr-16) and reverse primers ending at nucleotides 829 (Tr-18), 1,009 (Tr-22), and 1,234 (Tr-26). We obtained RT-PCR products with estimated sizes of $850,1,000$, and $1,250 \mathrm{bp}$ with the primer pairs of $\operatorname{Tr}-16 / \operatorname{Tr}-18, \operatorname{Tr}-16 / \operatorname{Tr}-22$, and Tr-16/Tr-26, respectively (Fig. 3B), indicating that the 5' NTR sequence obtained by cDNA clones and the 5' RACE system are, indeed, authentic.

TABLE 1. Putative proteinase cleavage sites in Triticum mosaic virus polyprotein

\begin{tabular}{llc}
\hline Proteinase & Peptide junction & Amino acid sequence \\
\hline P1 & P1/HC-Pro & EGLTYY/S \\
HC-Pro & HC-Pro/P3 & KDYRIG/G \\
$\mathrm{NIa}$ & $\mathrm{P} 3 / 6 \mathrm{~K} 1$ & EDYVLH/A \\
$\mathrm{NIa}$ & $6 \mathrm{~K} 1 / \mathrm{CI}$ & DSFVFH/A \\
$\mathrm{NIa}$ & $\mathrm{CI} / 6 \mathrm{~K} 2$ & $\mathrm{DCLVFH} / \mathrm{G}$ \\
$\mathrm{NIa}$ & $6 \mathrm{~K} 2 / \mathrm{NIa}-\mathrm{VPg}$ & EKYVMH/G \\
$\mathrm{NIa}$ & $\mathrm{NIa}-\mathrm{VPg} / \mathrm{NIa}-\mathrm{Pro}$ & $\mathrm{DNYVPH} / \mathrm{S}$ \\
$\mathrm{NIa}$ & $\mathrm{NIa}-\mathrm{Pro} / \mathrm{NIb}$ & SEFIFH/N \\
$\mathrm{NIa}$ & $\mathrm{NIb} / \mathrm{CP}$ & DEFVFH/S \\
\hline
\end{tabular}

The 739-nt-long 5' NTR of TriMV resembles those of species within the family Picornaviridae, whose leader sequences range in size from $628 \mathrm{nt}$ (Human rhinovirus B; GenBank accession no. NC_001490) to 1,039 nt (Foot-and-mouth disease virus type C; GenBank accession no. NC_002554) and contain internal ribosome entry site (IRES) elements (4). Interestingly, the 5' NTR of TriMV contains 12 translation initiation codons (AUG) in all three reading frames preceding the translation initiation codon of the polyprotein (Fig. 4A), which is unusual for 5'-leader sequences of most RNA plant viruses. Moreover, we observed three small ORFs (sORFs) in the $5^{\prime}$-leader sequence either within the $5^{\prime}$ NTR (sORF2) or overlapping with the $5^{\prime}$ of the polyprotein (sORFs1 and -3) (Fig. 4B). sORF1 encodes 61 amino acids in reading frame 1 from nucleotides 598 to 783; sORF2 encodes 33 amino acids in reading frame 2 from nucleotides 281 to 382 ; and sORF3 with a start codon at nucleotide 525 and ending at nucleotide 758 in reading frame 3 with 77 amino acids (Fig. 4B). Blast searches revealed that there is no significant homology of proteins encoded by SORFs with other reported protein sequences in GenBank.

Sequence comparison of TriMV mature proteins with those of other members of the family Potyviridae. Pairwise comparisons of amino acid identities of 10 mature proteins of TriMV with those of PYV and SCMV (Potyvirus), RGMV and AgMV (Rymovirus), MacMV (Macluravirus), Cucumber vein yellowing virus (CVYV) and SPMMV (Ipomovirus), WSMV and BrSMV (Tritimovirus), BaYMV (Bymovirus), and BIVY and SCSMV (unassigned members) clearly indicate that TriMV is a distinct species in the family Potyviridae (Table 2). As observed with other potyvirid species, NIb of TriMV shared the highest amino acid identity (33 to $65 \%$ ) with the corresponding protein of other

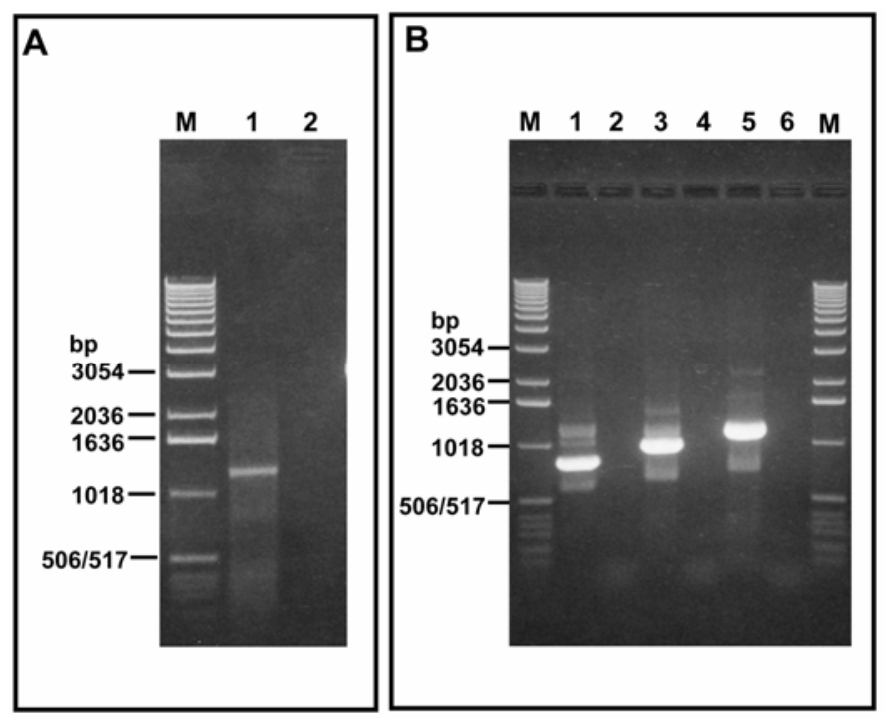

Fig. 3. Analysis of $5^{\prime}$ nontranslated region of Triticum mosaic virus (TriMV). A, Agarose gel electrophoresis (1\% in $1 \times$ Tris-acetate EDTA [TAE] buffer) of 5' rapid amplification of cDNA ends product of TriMV RNA. Gene-specific primer complementary to nucleotides 1240 to 1208 used for reverse transcription, followed by polymerase chain reaction (PCR) amplification with gene-specific primer complementary to nucleotides 1197 to 1165 and an abridged anchor primer (supplied with kit). Lane 1: C-tailed cDNA as the template for PCR; lane 2: cDNA without C-tailing as the template (negative control); lane M: DNA size markers. B, Agarose gel electrophoresis (1\% in 1× TAE buffer) of reverse-transcription PCR products with extreme $5^{\prime}$ end primer (forward primer, Tr-16) and reverse primers at different locations in the TriMV RNA. Lanes 1, 3, and 5: TriMV cDNA used for PCR; lanes 2, 4, and 6: water control. Lanes 1 and 2: PCR with $\operatorname{Tr}-16$ ( $5^{\prime}$ end primer) and $\operatorname{Tr}-18$ (complementary to nucleotides 829 to 812 ) primer pair; lanes 3 and 4: PCR with Tr-16 and Tr-22 (complementary to nucleotides 1009 to 992) primer pair; and lanes 5 and 6: PCR with Tr-16 and Tr-26 (complementary to nucleotides 1234 to 1217 ) primer pair. cDNA reverse transcribed with primer Tr-26 was used for PCR amplifications. 
members of the family Potyviridae (Table 2). P1 was the most diverse protein, with amino acid identity ranging from $15 \%$ (SPMMV and BlVY) to 29\% (BrSMV) (Table 2). HC-Pro, P3, 6K1, CI, 6K2, NIa-VPg, NIa-Pro, and CP of TriMV shared low levels of amino acid identities (13 to $33 \%$ ) with the corresponding proteins of members of the family Potyviridae, except with SCSMV (Table 2). Thus, among the members of Potyviridae that were used for sequence comparisons, TriMV proteins showed the highest amino acid identities with the corresponding proteins of SCSMV (Table 2). However, the degree of amino acid identity was relatively low (47 to 65\%). Only the nucleotide sequence encompassing 6K2 through the $3^{\prime}$ end is available for SCSMV; thus, amino acid identities of P1 through CI between TriMV and SCSMV are not known.

Phylogenetic relationships within the family Potyviridae. Phylogenetic analysis was performed using the NJ method with the complete polyprotein, CI, NIa-Pro, NIa-VPg, NIb, and CP sequences of representative virus species from different genera and unassigned members within the family Potyviridae. Phylogenetic trees with polyprotein and CI sequences resulted in similar topologies, whereas NIb and NIa-Pro sequences produced similar tree topologies but were slightly different from those of the polyprotein and CI sequences (data not shown). Thus, representative trees based on polyprotein and $\mathrm{NIb}$ sequences, in addition to NIa-VPg and CP, are presented in Figure 5. Similar phylogenetic trees were observed depicting the genetic relatedness among Potyvirus taxa with maximum likelihood analysis based on complete nucleotide sequence and NIb protein sequence (data not shown).

Phylogenetic analyses based on complete polyprotein, $\mathrm{NIb}$, and CP sequences placed TriMV (and SCSMV) in a separate branch between the members of Tritimovirus and Ipomovirus, such that three groups of viruses form a distinct clade within the family Potyviridae (Fig. 5A, B, and D). Trees representing the phylogenetic relationship based on mature protein sequences placed TriMV and SCSMV as sister taxa which share a most recent common ancestor with the members of Ipomovirus (with NIb and NIa-Pro) or Tritimovirus (with polyprotein and CP). Analysis with NIa-VPg protein yielded a poorly resolved phylogenetic tree which, nevertheless, showed that TriMV and SCSMV are sister taxa (Fig. 5C). In summary, TriMV and SCSMV formed a clade with tritimo- and ipomoviruses in phylograms generated with polyprotein and analyzed mature proteins of potyviruses, except with NIa-VPg (Fig. 5).

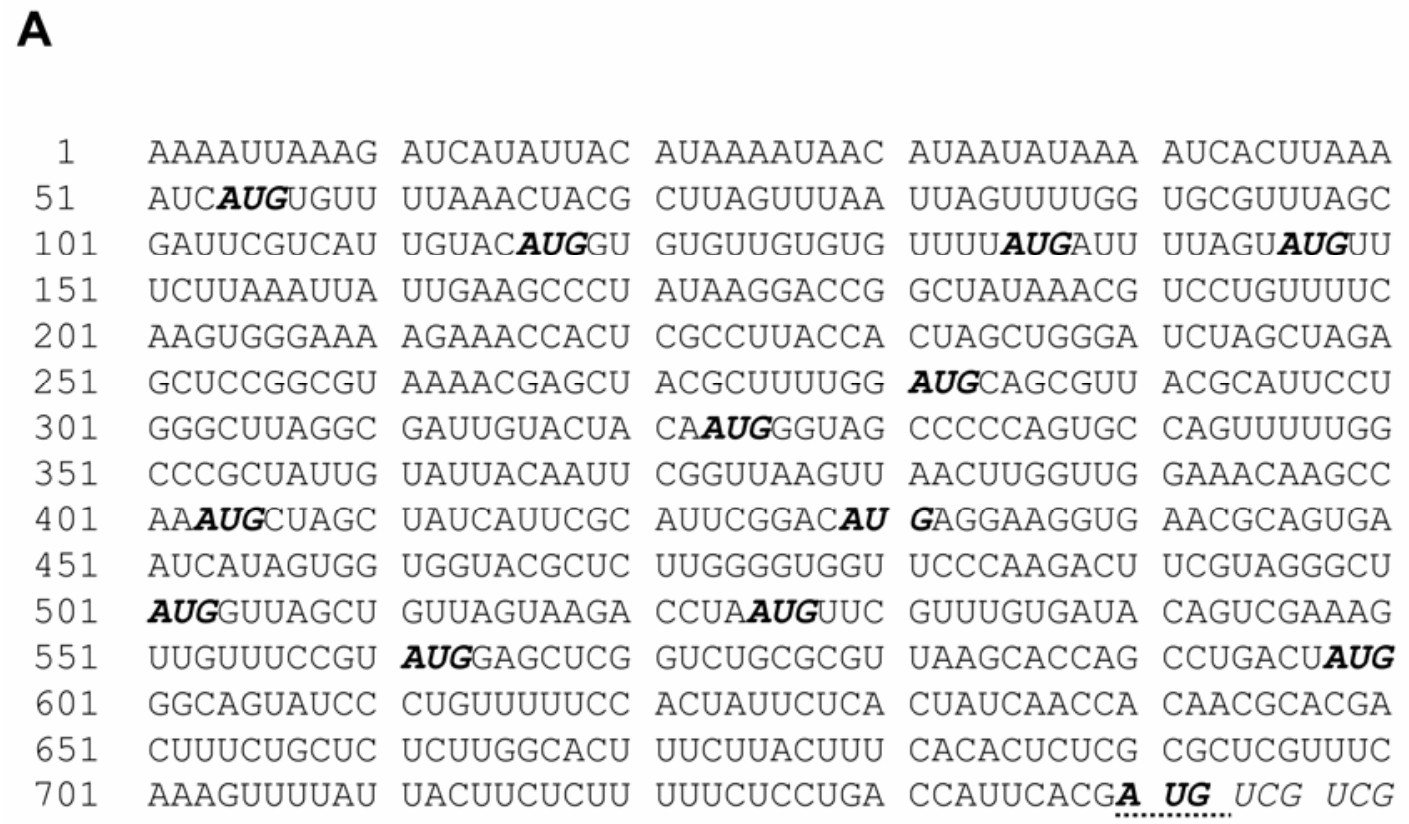

\section{B}

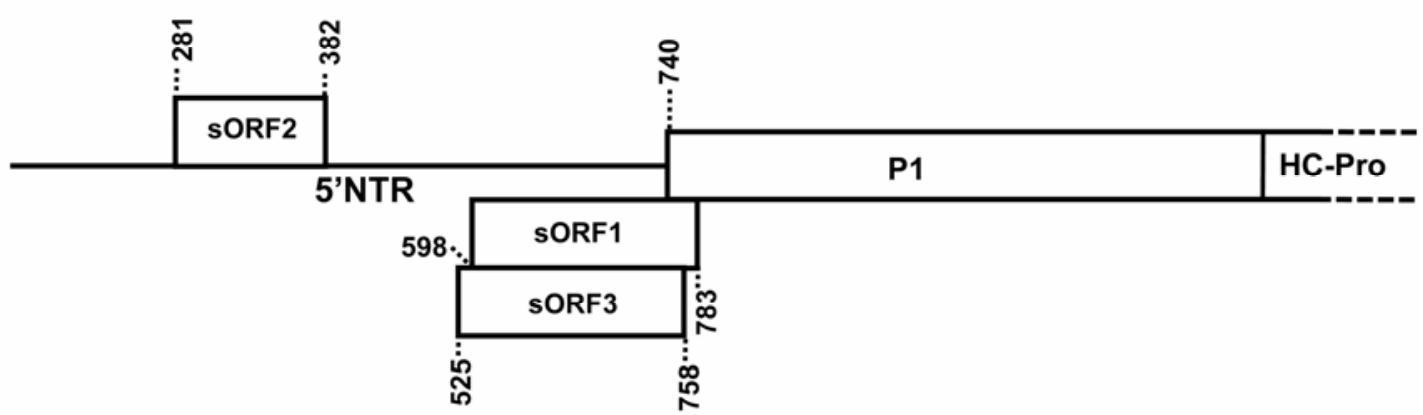

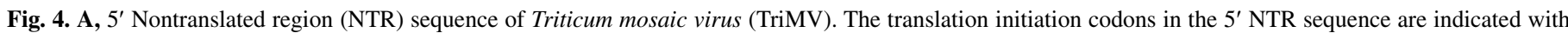

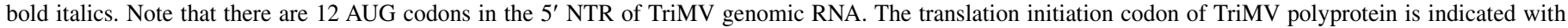

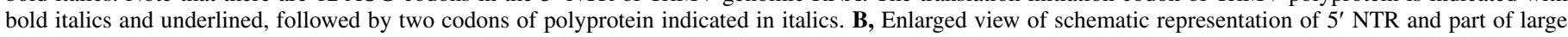

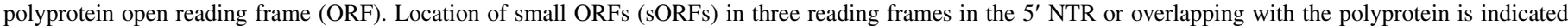

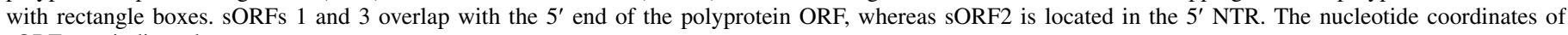
sORFs are indicated. 


\section{DISCUSSION}

The taxonomic position of TriMV in the family Potyviridae was examined by sequencing its genome completely, and it was found that the mature proteins of TriMV possess 13 to $65 \%$ amino acid identity with the corresponding proteins of representative members in the family Potyviridae. Based on substantial amino acid sequence divergence between TriMV and representative members in other genera of the Potyviridae, a separate genus is proposed for TriMV: the genus Poacevirus, with TriMV as the type species and SCSMV as a distinct member. TriMV and SCSMV should be considered as two distinct species in the genus Poacevirus, because the mature proteins (6K2, NIa, NIb, and CP) of these two viruses differ by 35 to $53 \%$ in amino acid identity, which greatly exceeds the species demarcation threshold $(<80 \%$ amino acid identity) to establish new virus species $(2,5)$. Recently, Viswanathan et al. (27) reported CP sequences of several isolates of SCSMV and proposed a new genus, Susmovirus, with SCSMV as the sole member. However, the complete genome sequence of a tentative member species is required before a new genus classification may be considered (2). Thus, we propose the name Poacevirus for a new genus that would encompass TriMV and SCSMV. The genus Poacevirus was proposed because TriMV and SCSMV naturally infect the Poaceae members wheat and sugarcane, respectively.

Even though TriMV has a genome organization similar to monopartite viruses in the genera Potyvirus, Rymovirus, and Tritimovirus, the 5' NTR of TriMV is unusually long, with $739 \mathrm{nt}$, which is four to seven times longer than other reported members of the family Potyviridae. Interestingly, the family Picornaviridae, which contains viruses infecting humans, animals, and birds, possesses long 5' NTR sequences (628 to $1039 \mathrm{nt}$ ), which is highly structured to form an IRES element for protein translation as well as high-order structures responsible for genome replication, both of which are critical for virulence $(4,8)$. The families Potyviridae and Picornaviridae belong to an evolutionarily similar lineage of a Picorna-like virus superfamily with conserved genomic organization and expression strategy (13). Additionally, the presence of 12 translation initiation codons and three sORFs with 33 to 77 amino acids in the leader sequence of TriMV is a unique feature for a potyvirid species. Two of these sORFs (sORF1 and -3; 61 and 77 amino acids) located in the 5' NTR are larger than the $6 \mathrm{~K} 1$ and $6 \mathrm{~K} 2$ cistrons (50 to 56 amino acids) of TriMV, and the $3^{\prime}$ ends of these sORFs overlap slightly with the ORF encoding a large polyprotein. The role of these sORFs in virus biology is not known and can be examined after the availability of an infectious cDNA clone. The 5'-leader sequences of Picornaviridae members also possess several AUG codons preceding the polyprotein translation initiation codon. The 712-nt leader sequence of Aichi virus (GenBank accession no. NC_001918) contains 6 AUGs, and a 628-nt leader sequence of Human rhinovirus B (GenBank accession no. NC_001490) possesses 13 AUG codons preceding the translation initiation of polyprotein. The 5' NTR of Picornaviridae members also encodes one to three sORFs with 36 to 165 amino acids, although the function of these small ORFs in virus biology is not known.

Multiple initiation codons upstream of the translation initiation codon of a polyprotein would substantially downregulate the ability of ribosomes to recognize the translation initiation codon of the polyprotein. Then, how would TriMV overcome these translation "road blocks" in the eukaryotic translation system? It is possible that the long 5'-leader sequence of TriMV might play an important role in translation of the polyprotein, like an IRES element as reported for the members of Picornaviridae (15). Although the 5' NTR of TriMV folded into several stem-and-loop structures by MFOLD program (data not shown), we do not know whether the TriMV leader sequence contains an IRES element similar to the Picornaviridae members. Nevertheless, resemblances between the leader sequences of TriMV (a potyvirid) and the Picornaviridae members, both belonging to the Picorna-like superfamily, suggests that the $5^{\prime}$ NTR of TriMV might contain an IRES element or equivalent structure, which would involve capindependent translation of TriMV mRNA. Because the complete genome sequence of SCSMV is not available, it is not known whether the long $5^{\prime}$ NTR is the characteristic feature of the proposed new genus.

The putative cleavage sites of TriMV and SCSMV NIaproteinase in the polyprotein were identified between histidine ( -1 position) and alanine, glycine, serine, or asparagine at the +1 position, which is not found in the vast majority of other members of the family Potyviridae. The conserved histidine residue at the -1 position of NIa-Proteinase cleavage sites in TriMV and SCSMV, together with relatively high amino acid sequence identity of mature proteins (6K2, NIa, NIb, and $\mathrm{CP}$ ), strongly support the idea that these two viruses form sister taxa in the new genus. Adams et al. (1) inferred that the NIa proteinase cleavage sites of SPMMV also have a histidine residue at the -1 (substrate P1) position. Structural features of the NIb proteinase of TEV have been identified including two residues, threonine-146 and histidine-167, which are part of the binding pocket (S1) that

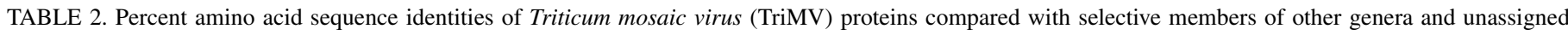
members in the family Potyviridea ${ }^{\text {a }}$

\begin{tabular}{|c|c|c|c|c|c|c|c|c|c|c|c|c|}
\hline \multirow[b]{2}{*}{ Cistron } & \multicolumn{2}{|c|}{ Potyvirus } & \multicolumn{2}{|c|}{ Rymovirus } & \multirow{2}{*}{$\frac{\text { Macluravirus }}{\text { MacMV }}$} & \multicolumn{2}{|c|}{ Ipomovirus } & \multicolumn{2}{|c|}{ Tritimovirus } & \multirow{2}{*}{$\frac{\text { Bymovirus }}{\text { BaYMV }}$} & \multicolumn{2}{|c|}{ Unassigned } \\
\hline & PYV & SCMV & RGMV & AgMV & & CVYV & SPMMV & WSMV & BrSMV & & BlVY & SCSMV \\
\hline $\mathrm{P} 1$ & 17.6 & 16.5 & 17.1 & 16.3 & - & $18.5^{\mathrm{b}}$ & 15.0 & 26.9 & 28.7 & 17.4 & 15.0 & - \\
\hline HC-Pro & 20.4 & 19.0 & 21.8 & 20.5 & - & $20.9^{c}$ & 20.4 & 21.1 & 19.5 & $n p^{d}$ & 20.4 & - \\
\hline P3 & 17.3 & 19.5 & 19.3 & 19.2 & - & 17.6 & 18.4 & 19.7 & 19.9 & 20.1 & 20.1 & - \\
\hline $6 \mathrm{~K} 1$ & 19.3 & 14.9 & 21.1 & 19.6 & - & 19.3 & 12.5 & 17.9 & 22.8 & 17.9 & 17.5 & - \\
\hline CI & 25.5 & 26.1 & 29.0 & 27.6 & - & 24.8 & 24.3 & 29.2 & 25.6 & 24.5 & 23.4 & - \\
\hline $6 \mathrm{~K} 2$ & 13.5 & 22.6 & 18.3 & 17.0 & - & 21.8 & 26.4 & 21.6 & 33.3 & 10.7 & 20.6 & 54.0 \\
\hline NIa-VPg & 22.7 & 22.0 & 21.4 & 21.3 & - & 24.8 & 24.5 & 22.9 & 17.7 & 21.6 & 20.9 & 49.0 \\
\hline NIa-Pro & 20.2 & 22.1 & 22.4 & 23.0 & - & 31.1 & 24.4 & 25.4 & 24.2 & 19.2 & 23.0 & 46.9 \\
\hline $\mathrm{NIb}$ & 37.9 & 38.7 & 39.4 & 38.7 & - & 43.7 & 40.7 & 41.3 & 43.1 & 32.6 & 38.4 & 65.2 \\
\hline $\mathrm{CP}$ & 22.9 & 22.0 & 23.6 & 20.4 & 19.0 & 24.7 & 25.8 & 25.6 & 29.6 & 21.0 & 18.7 & 48.3 \\
\hline
\end{tabular}

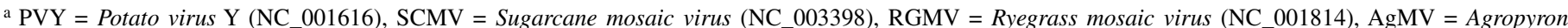
mosaic virus (NC_005903), MacMV = Maclura mosaic virus (U58771), CVYV= Cucumber vein yellowing virus $(\mathrm{AY} 578085)$, SPMMV = Sweet potato mild mottle virus $\left(\mathrm{NC} \_003797\right), \mathrm{WSMV}=$ Wheat streak mosaic virus $\left(\mathrm{NC} \_001886\right), \mathrm{BrSMV}=$ Brome streak mosaic virus $\left(\mathrm{NC} \_003501\right)$, BaYMV = Barley yellow mosaic virus (NC_002990), BIVY = Blackberry virus Y (NC_008558), and SCSMV = Sugarcane streak mosaic virus (Y17738); - indicates sequence data not available.

b Compared with P1a.

c Compared TriMV P1 with CVYV P1b.

${ }^{\mathrm{d}} \mathrm{HC}$-Pro cistron is not present. 
directly interact with the substrate P1 position (16). These two residues are strictly conserved among members of the Potyviridae, where the substrate $\mathrm{P} 1$ ( -1 position) is either glutamine or glutamic acid. Interestingly, the homologous $\mathrm{S} 1$ residues are threonine-asparagine in NIa of SPPMV rather than threoninehistidine. Molecular modeling suggests that the histidine to asparagine substitution would accommodate docking of substrate peptides bearing histidine at substrate $\mathrm{P} 1$ position in the cleavage site (1). The homologous S1 residues in the NIas of both TriMV and SCSMV are serine-histidine. It is possible that replacement of threonine with the smaller serine residue may similarly accommodate the presence of histidine at substrate $\mathrm{P} 1$ ( -1 position).
The fact that phylogenetic analysis of the complete polyproteins or mature proteins of selected members of the family Potyviridae consistently placed TriMV and SCSMV together on a separate branch from other reported potyvirid species provides further evidence that these two viruses represent sister taxa in a new genus. TriMV and SCSMV share a most recent common ancestor with the members of Tritimovirus, mite-transmitted viruses (based on polyprotein and $\mathrm{CP}$ sequences), or with Ipomovirus, whitefly-transmitted viruses (based on NIb sequence), suggesting that vector transmission criteria may not be used alone for taxonomic classification of potyviruses, because the mite-transmitted viruses were grouped into phylo-

\section{A Polyprotein}

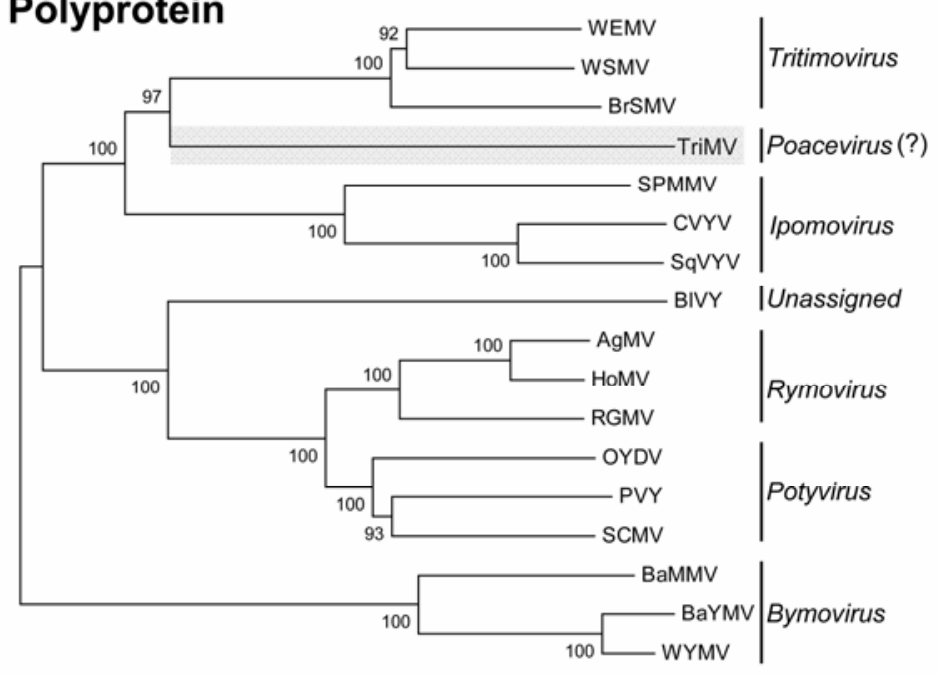

0.2

\section{Nla-VPg}
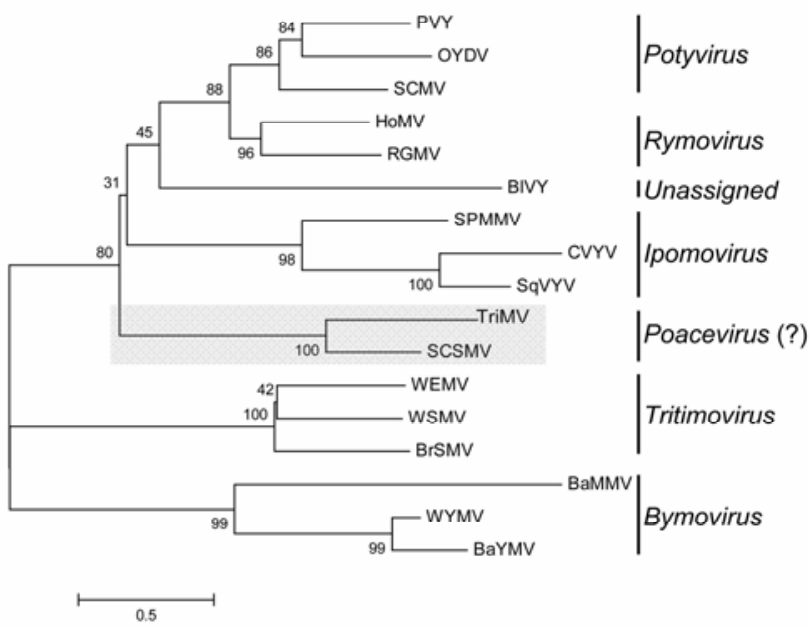

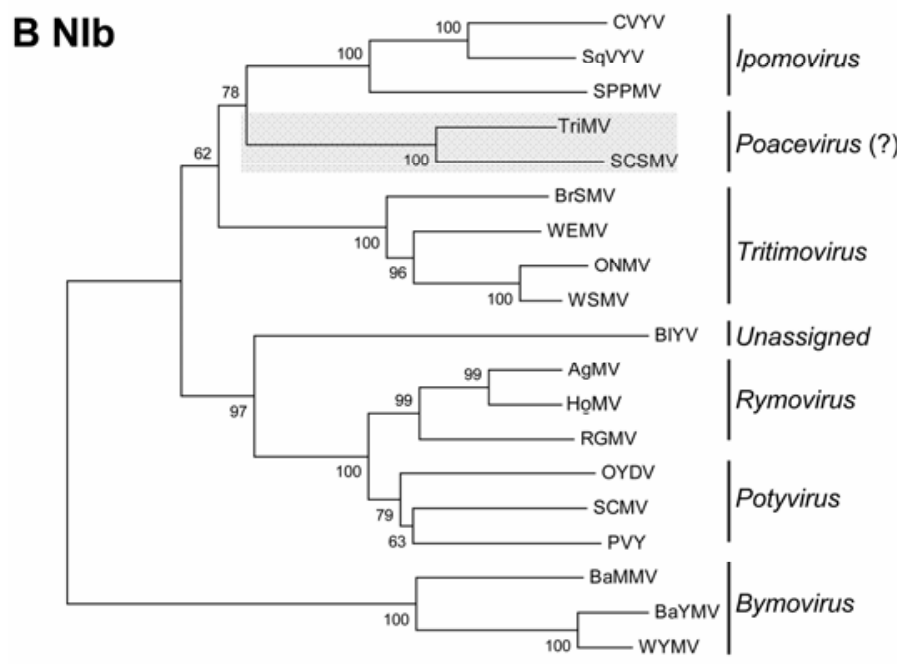

D CP

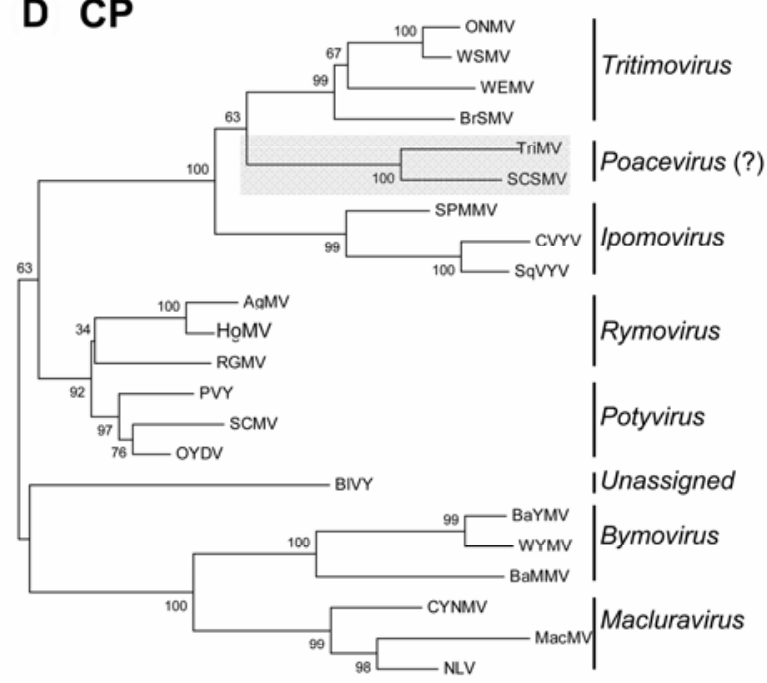

0.2

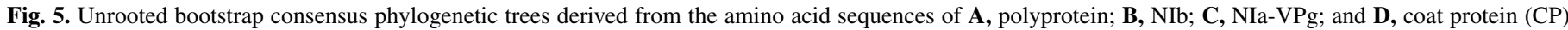

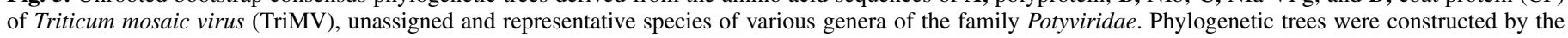

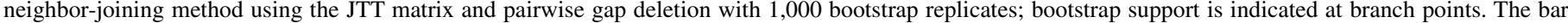

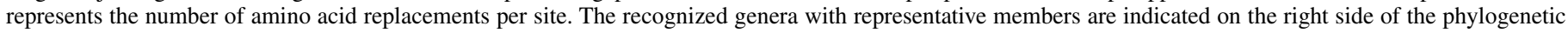

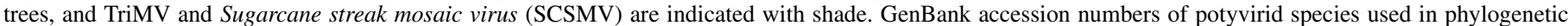

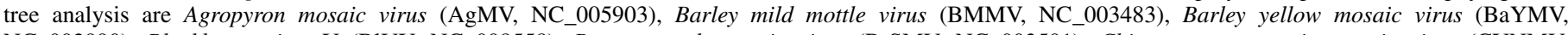

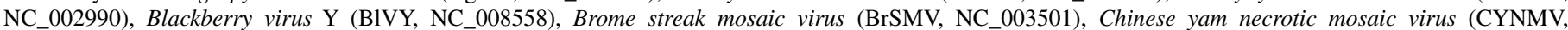

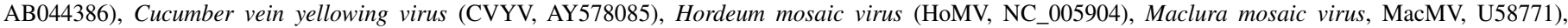

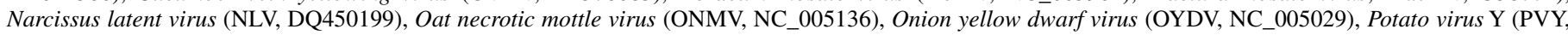

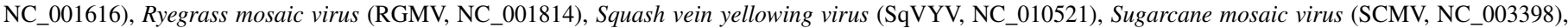

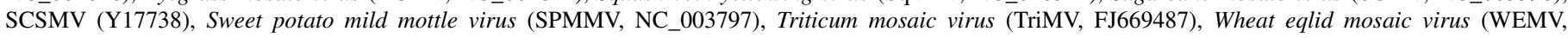
NC_009805), Wheat streak mosaic virus (WSMV, NC_001886), and Wheat yellow mosaic virus (WYMV, NC_002350). 
genetically distinct genera Tritimovirus, Rymovirus, and Poacevirus (TriMV).

Taken together, the unusually long 5'-leader sequence with several translation initiation codons and sORFs, low amino acid sequence identity with representative members of the genera in the family Potyviridae, and relatively high (47 to 65\%) amino acid identity with mature proteins of SCSMV suggest that TriMV should be placed in a new genus, Poacevirus, as the type species, with SCSMV as a distinct member.

\section{ACKNOWLEDGMENTS}

We thank S. Gowda for critical reading of the manuscript. Mention of proprietary or brand names are necessary to report factually on available data; however, the United States Department of Agriculture (USDA) neither guarantees nor warrants the standard of the product, and the use of the name by USDA implies no approval to the exclusion of others that also may be suitable.

\section{LITERATURE CITED}

1. Adams, M. J., Antoniw, J. F., and Beaudoin, F. 2005. Overview and analysis of the polyprotein cleavage sites in the family Potyviridae. Mol. Plant Pathol. 6:471-487.

2. Adams, M. J., Antoniw, J. F., and Fauquet, C. M. 2005. Molecular criteria for genus and species discrimination within the family Potyviridae. Arch. Virol. 150:459-479.

3. Bailey, J. M., and Davidson, N. 1976. Methylmercury as a reversible denaturing agent for agarose gel electrophoresis. Anal. Biochem. 70:7585 .

4. Belsham, G. J. 2009. Divergent picornavirus IRES elements. Virus Res. 139:183-192

5. Berger, P. H., Adams, M. J., Barnett, O. W., Brunt, A. A., Hammond, J., Hill, J. H., Jordan, R. L., Kashiwazaki, S., Rybicki, E., Spence, N., Stenger, D. C., Ohki, S. T., Uyeda, I., van Zaayen, A., Valkonen, J., and Vetten, H. J. 2005. Pages 819-841 in: Virus Taxonomy-Classification and Nomenclature of Viruses, 8th Report of the ICTV. C. M. Fauquet, M. A. Mayo, J. Maniloff, U. Desselberger, and L. A. Ball, eds. Elsevier Academic Press, San Diego, CA.

6. Brakke, M. K. 1987. Virus disease in wheat. Pages 585-603 in: Wheat and Wheat Improvement, 2nd ed. E. G. Heyne, ed. American Society of Agronomy, Crop Science Society of America, Soil Science Society of America, Madison, WI.

7. Chung, B. Y.-W., Miller, W. A., Atkins, J. F., and Firth, A. E. 2008. An overlapping essential gene in the Potyviridae. Proc. Natl. Acad. Sci. USA 105:5897-5902.

8. Fernández-Miragall, O., López de Quinto, S., and Martínez-Salas, E. 2009. Relevance of RNA structure in the activity of picornavirus IRES elements. Virus Res. 139:172-182.

9. Götz, R., Huth, W., Lesemann, D. E., and Maiss, E. 2002. Molecular and serological relationships of Spartina mottle virus (SpMV) strains from Spartina spec. and from Cynodon dactylon to other members of the Potyviridae. Arch. Virol. 147:379-391.

10. Hall, J. S., Adams, B., Parsons, T. J., French, R., Lane, L. C., and Jensen, S. G. 1998. Molecular cloning, sequencing and phylogenetic relationships of a new potyvirus: sugarcane streak mosaic virus and a reevaluation of the classification of the Potyviridae. Mol. Phylogenet. Evol. 10:323-332.
11. Hema, M., Joseph, J., Gopinath, K., Sreenivasulu, P., and Savithri, H. S. 1999. Molecular characterization and interviral relationships of a flexuous filamentous virus causing mosaic disease of sugarcane (Saccharum officinarum) in India. Arch. Virol. 144:479-490.

12. Hema, M., Sreenivasulu, P., and Savithri, H. S. 2002. Taxonomic position of sugarcane streak mosaic virus in the family Potyviridae. Arch. Virol. 147:1997-2007.

13. Koonin, E. V., Wolf, Y. I., Nagasaki, K., and Dolja, V. V. 2008. The big bang of picorna-like virus evolution antedates the radiation of eukaryotic supergroups. Nat. Rev. 6:925-939.

14. Lane, L. C. 1986. Propagation and purification of RNA plant viruses. Methods Enzymol. 118:687-696.

15. Martínez-Salas, E., Pacheco, A., Serrano, P., and Fernandez, N. 2008. New insights into internal ribosome entry site elements relevant for virus gene expression. J. Gen. Virol. 89:611-626.

16. Phan, J., Zdanov, E., Evdokimov, A. G., Tropea, J. E., Peters, H. K., Kapust, R. B., Li, M., Wlodawer, A., and Waugh, D. S. 2002. Structural basis for the substrate specificity of Tobacco etch virus protease. J. Biol. Chem. 277:50564-50572.

17. Rabenstein, F., Seifers, D. L., Schubert, J., French, R., and Stenger, D. C. 2002. Phylogenetic relationships, strain diversity and biogeography of tritimoviruses. J. Gen. Virol. 83:895-906.

18. Schaad, M. C., Haldeman-Cahill, R., Cronin, S., and Carrington, J. C. 1996. Analysis of the VPg-Proteinase (NIa) encoded by tobacco etch potyvirus: effects of mutations on subcellular transport, proteolytic processing, and genome amplification. J. Virol. 70:7039-7048.

19. Seifers, D. L., Martin, T. J., Harvey, T. L., Fellers, J. P., and Michaud, J. P. 2009. Identification of the wheat curl mite as the vector of Triticum mosaic virus. Plant Dis. 93:25-29.

20. Seifers, D. L., Martin, T. J., Harvey, T. L., Fellers, J. P., Stack, J. P., RybaWhite, M., Haber, S., Krokhin, O., Spicer, V., Lovat, N., Yamchuk, A., and Standing, K. G. 2008. Triticum mosaic virus: a new virus isolated from wheat in Kansas. Plant Dis. 92:808-817.

21. Skare, J. M., Wijkamp, I., Denham, I., Rezende, J. A. M., Kitajima, E. W., Park, J.-W., Desvoyes, B., Rush, C. M., Michels, G., Scholthof, K. B. G., and Scholthof, H. B. 2006. A new eriophyid mite-borne membraneenveloped virus-like complex isolated from plants. Virology 347:343-353.

22. Stenger, D. C., Hall, J. S., Choi, I.-R., and French, R. 1998. Phylogenetic relationships within the family Potyviridae: wheat streak mosaic virus and brome streak mosaic virus are not members of the genus Rymovirus. Phytopathology 88:782-787.

23. Susaimuthu, J., Tzanetakis, I. E., Gergerich, R. C., and Martin, R. R. 2008. A member of a new genus in the Potyviridae infects Rubus. Virus Res. 131:145-151.

24. Tamura, K., Dudley, J., Nei, M., and Kumar, S. 2007. MEGA4: Molecular Evolutionary Genetics Analysis (MEGA) software version 4.0. Mol. Biol. Evol. 24:1596-1599.

25. Thompson, J. D., Gibson, T. J., Plewniak, F., Jeanmougin, F., and Higgins, D. 1997. The ClustalX windows interface: flexible strategies for multiple sequence alignment aided by quality analysis tools. Nucleic Acids Res. 24:4876-4882.

26. Valli, A., López-Moya, J. J., and García, J. A. 2007. Recombination and gene duplication in the evolutionary diversification of P1 proteins in the family Potyviridae. J. Gen. Virol. 88:1016-1028.

27. Viswanathan, R., Balamuralikrishnan, M., and Karuppaiah, R. 2008. Characterization and genetic diversity of Sugarcane streak mosaic virus causing mosaic in sugarcane. Virus Genes 36:553-564.

28. Wegulo, S., Hein, G., and Ziems, A. 2009. Wheat disease update. Page 133 in: Proc. 2009 Crop Production Clinics. University of NebraskaLincoln Extension. 